\title{
Healthcare utilization after stroke in Canada- a population based study
}

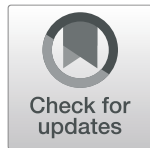

\author{
Adebimpe O. Obembe ${ }^{1,2}$, Lisa A. Simpson ${ }^{2,3}$, Brodie M. Sakakibara ${ }^{1,2}$ and Janice J. Eng ${ }^{1,2^{*}}$
}

\begin{abstract}
Background: More people are surviving stroke but are living with functional limitations that pose increasing demands on their families and the healthcare system. The aim of this study was to determine the extent to which stroke survivors use healthcare services on a population level compared to people without a stroke.

Methods: This was a cross-sectional population-based survey that collected information related to health status, healthcare utilization and health determinants using the 2014 Canadian Community Health Survey. Healthcare utilization was assessed by a computer-assisted personal interview asking about visits to healthcare professionals in the last 12 months. Negative binomial regression was used to estimate the incidence rate ratios (IRR) and 95\% confidence intervals (CI) for the number of health professional visits between stroke survivors and people without a stroke. The regression models were adjusted for demographics, as well as for mobility, mood/anxiety disorder and cardiometabolic comorbid conditions.

Results: The study sample included 35,759 respondents (948 stroke, 34,811 non-stroke) and equate to 12,396,641 (286,783 stroke; $12,109,858$ non-stroke) when sampling weights were applied. Stroke survivors visited their family doctor the most, and stroke was significantly associated with more visits to most healthcare professionals [e.g., family doctor IRR 1.6 (Cl 1.4-1.8); nurse IRR 3.0 (Cl 1.8-4.8); physiotherapist IRR 1.8 (Cl 1.1-1.9); psychologist IRR 4.0 (Cl 1.1-5.7)] except the dental practitioner, which was less [IRR 0.7 (Cl 0.6-0.9)]. Mood/anxiety condition, but not cardiometabolic comorbid condition increased the probability of visiting a family doctor or social worker/ counsellor among people with stroke.
\end{abstract}

Conclusion: Stroke survivors visited healthcare professionals more often than people without stroke, and were approximately twice as likely to visit with those who manage problems that may arise after a stroke (e.g., family doctor, nurse, psychologist, physiotherapist). The effects of a stroke include mobility impairment and mood/ anxiety disorders. Therefore, adequate access to stroke-related healthcare services should be provided for stroke survivors, as this may improve functional outcome and reduce future healthcare costs.

Keywords: Stroke, Healthcare utilization, Health services, Mobility

\section{Background}

Stroke is a leading cause of long-term disability in adults worldwide [1] and it can be devastating to individuals. After age 55, there is a lifetime risk of stroke of 1 in 5 for women and 1 in 6 for men [2]. Stroke can result in loss of independence with immense human and financial burden, which will magnify as the world-wide incidence

\footnotetext{
* Correspondence: janice.eng@ubc.ca

'Department of Physical Therapy, The University of British Columbia, Vancouver, Canada

${ }^{2}$ Rehabilitation Research Program, GF Strong Rehab Centre, Vancouver

Coastal Health Research Institute, Vancouver, Canada

Full list of author information is available at the end of the article
}

of stroke and stroke survivors continue to increase [3]. Donabedian [4] defined health utilization as the outcome of the interaction between health professionals and patients. Health utilization is a multidimensional process that includes indicators such as quality of care, accessibility, efficiency, equity, volume, continuity, comprehensiveness, productivity of care and healthcare expenses. [5]. Several factors (e.g. demographics, physical, psychological) might influence how stroke survivors use healthcare services [6-8]. In Canada, about 85 to $90 \%$ of stroke survivors return to their own environment with or without support services $[9,10]$. While there are

(c) The Author(s). 2019 Open Access This article is distributed under the terms of the Creative Commons Attribution 4.0 International License (http://creativecommons.org/licenses/by/4.0/), which permits unrestricted use, distribution, and 
some data that suggest that stroke survivors may utilize greater healthcare services after their stroke $[7,8,11$, 12], studies have not compared this utilization using a control group. Impaired functional health, higher financial income, younger age, emotional distress [8], pre-stroke dependency [7], living arrangement, social circumstances [7] and access to a physician [6] have been associated with the use of healthcare services after stroke. Stroke survivors living at home have reported unmet needs in several domains, including mobility, mood, communication, health provision after discharge and managing stroke-related problems [13, 14]. These factors could plausibly affect healthcare utilization after stroke but their association has never been established.

Two-thirds of patients with a first stroke survive after 3 years, and the risk of surviving is lowest in the first year [15]. Pre-existing medical conditions, especially cardiometabolic conditions, are common among stroke patients, and can affect functional outcome [16]. Providing care for stroke survivors can be complex, requiring a continuum of coordinated health and support services which may include physicians and other allied health team members [17], although the utilization of these healthcare services has never been reported in a nationally representative population-based study of stroke survivors living in the community. It is widely recognized that healthcare systems lack continuity across services and are often criticized for shortening hospital length-of-stay and offering limited community services [18]. Therefore, the purpose of this study was to determine the effect of having a stroke on the annual visit rates to healthcare professionals using a population-based sample of community-dwelling adults in Canada. Given the multiple physical and cognitive impairments common in stroke, in addition to numerous pre-existing co-morbidities, we hypothesized that stroke survivors would utilize greater healthcare services compared to people without stroke.

\section{Methods}

Data source

Data were from the 2014 Canadian Community Health Survey- Annual Component (CCHS), a cross-sectional survey that collected information related to health status, healthcare utilization and health determinants for the Canadian population. Statistics Canada data did not require an ethics review as it is a secondary analysis, however, a proposal on the use of the data was approved by Statistics Canada. The CCHS covers the population 12 years of age and above, and living in private households in the ten provinces and the three territories, and it relies upon a large sample of respondents. Persons living on reserves and other Aboriginal settlements; full-time members of the Canadian Forces; institutionalized persons, children aged 12-17 years that are living in foster care, and persons living in the Quebec health regions of Région du Nunavik and Région des Terres-Cries-de-la-Baie-James, were excluded from the survey. On the whole, these exclusions represent less than $3 \%$ of the Canadian population aged 12 years and older. Healthcare utilization was assessed by a computer-assisted personal interview asking about the number of visits to healthcare professionals [19]. Responding to the survey was voluntary. Respondents were asked whether they had conditions diagnosed by a healthcare professional that had lasted or was expected to last at least 6 months. Detailed descriptions of the survey are available elsewhere $[19,20]$.

\section{Inclusion and exclusion criteria}

Our inclusion criteria required that individuals be at least 50 years of age at the time of the interview. Healthcare utilization rises slowly throughout adult life, and increases exponentially after the age of 50 years [21]. While the mean age of stroke is 69 years (and decreasing) [22], approximately $20 \%$ of stroke survivors are between the ages of 50 and 69 years [23].

\section{Variables}

Respondents were stratified into two groups, stroke and non-stroke. The stroke group consisted of respondents who had suffered from the effects of a stroke that was expected to last or had already lasted 6 months or more [20]. The non-stroke group consisted of respondents who did not have a stroke and other major medical conditions (asthma, arthritis, cancer, chronic obstructive pulmonary disease, chemical sensitivity, scoliosis, back problem). Respondents were asked to provide information on age, sex, educational status, total household income and healthcare utilization. Respondents were asked how many times they had seen or talked to the following health professionals for care or advice about their physical, emotional or mental health in the last 12 months; family doctor or general practitioner, eye specialist, other medical specialists (e.g., allergist, orthopaedist, psychiatrist), nurse, dental practitioner (dentist/ dental hygienist/orthodontist), chiropractor, physiotherapist, psychologist, social worker/counsellor, and audiologist/speech/occupational therapist. Respondents were stratified by sociodemographic variables (male/female; $<$ or $\geq 65$ years of age; $<$ or $\geq \$ 40,000$ income) based on the literature. Individuals who are female, older and have a lower income have poorer outcomes after stroke $[24,25]$. Respondents were also stratified into presence and absence of the following; mobility (able to walk with/without difficulty), mood or anxiety disorder (e.g., depression, bipolar disorder, mania, dysthymia, phobia, obsessive-compulsive disorder or a panic disorder), and cardiometabolic comorbid conditions (hypertension, 
diabetes, heart disease). These variables were selected because these are chronic medical conditions that are more likely to occur in stroke survivors $[16,26,27]$ and it is well established that such physical and mental health impairments, as well as cardiometabolic comorbidities lead to poorer functioning [16] and quality of life $[24,25]$ after stroke.

\section{Statistical analysis}

Descriptive statistics of weighted frequency, percent, mean and standard deviation were used to summarize the data. To account for survey design effects such as clustering and unequal selection probabilities, and to ensure that the results were representative of the Canadian population, the set of replicate sampling weights developed for the CCHS 2014 by Statistics Canada was used for all analyses. Negative binomial regression with incidence rate ratios (IRR) and 95\% confidence intervals (CI) were used to investigate the association between variables. This technique is able to handle over-dispersed data as typically found with health provider visits [28]. Simple pair-wise associations (IRR and 95\% CI) between the number of visits for each health professional and age, sex, education, income, mobility, mood/anxiety disorder and cardiometabolic comorbid condition explored factors associated with health utilization in the stroke group. Models were then built to investigate the relationship between dependent variables (visits to each healthcare professional) and the independent variable (group - stroke versus non-stroke) (Crude Model). Adjusted IRR and 95\%
CI were determined after controlling for sociodemographic covariates - age, sex, education, income (Model 1). Three additional models were explored by separately adding mobility (Model 1a), mood/anxiety disorder (Model 1b) or cardiometabolic comorbid condition (Model 1c) to control for physical and mental health conditions in stroke survivors.

Alpha level was set at 0.05 . All analyses were performed with the IBM Statistical Package for Social Sciences (SPSS) for windows version 24.0 and Stata/ IC version 15 software package.

\section{Results}

The study sample consisted of 35,759 respondents (948 stroke survivors and 34,811 non-stroke) across Canada and equate to an estimated 12,396,641 (286,783 stroke survivors; 12,109,858 non-stroke) when sampling weights were used. The mean age of the sample was $63.6 \pm 10.0$ years and $52.3 \%$ were women. The stroke group (mean $=70.5 \pm 10.8$ years) was older than the non-stroke group (mean $=63.4 \pm 9.9$ years). The stroke group had 1.5, 1.8 and 2.0 times the proportion of people with a mobility condition, cardiometabolic condition or mood/anxiety disorder, respectively compared to the non-stroke group (Table 1).

The most common healthcare providers visited were the same between the stroke/non-stroke groups: family doctor (93.2\%/ 84.7\%), eye specialist (55.1\%/ 50.2\%), other medical specialists (54.0\%/ $36.8 \%)$ and dental practitioner $(43.9 \% / 64.2 \%)$. The mean number of visits with

Table 1 Characteristics of study sample from the 2014 Canadian Community Health Survey

\begin{tabular}{|c|c|c|c|}
\hline$\overline{N(\%)^{a}}$ & $\begin{array}{l}\text { Total } \\
12,396,641(100)\end{array}$ & $\begin{array}{l}\text { Stroke } \\
286,783(2.3)\end{array}$ & $\begin{array}{l}\text { Non-stroke group } \\
12,109,858 \text { (97.7) }\end{array}$ \\
\hline Age (Years) Mean (SD) & $63.6(10.0)$ & $70.5(10.8)$ & $63.4(9.9)$ \\
\hline \multicolumn{4}{|l|}{ Age (Years) n(\%) } \\
\hline$<65$ & $7,328,212(59.1)$ & $96,554(33.7)$ & $7,231,659(59.7)$ \\
\hline$\geq 65$ & $5,068,429(40.9)$ & $190,229(66.3)$ & $4,878,199(40.3)$ \\
\hline \multicolumn{4}{|l|}{ Sex n(\%) } \\
\hline Male & $5,911,848(47.7)$ & $153,493(53.5)$ & $5,758,355(47.6)$ \\
\hline Female & $6,484,793(52.3)$ & $133,290(46.5)$ & $6,351,503(52.4)$ \\
\hline \multicolumn{4}{|l|}{ Education n(\%) } \\
\hline$<$ High School & $1,455,086(11.7)$ & $66,868(23.3)$ & $1,388,218(11.5)$ \\
\hline$\geq$ High School & $10,941,555(88.3)$ & $219,915(76.7)$ & $10,721,639(88.5)$ \\
\hline \multicolumn{4}{|l|}{ Total Household Income (CAD) n(\%) } \\
\hline$<40,000$ & $3,849,612(31.1)$ & $140,730(49.1)$ & $3,708,881(30.6)$ \\
\hline$\geq 40,000$ & $8,547,029(68.9)$ & $146,053(50.9)$ & $8,400,977(69.4)$ \\
\hline Mobility (Able to walk without difficulty) Yes n(\%) & $11,205,716(90.4)$ & $171,802(59.9)$ & $11,033,914(91.1)$ \\
\hline Had at least one cardiometabolic comorbid condition (Yes) n(\%) & $5,350,149(43.2)$ & $213,043(74.3)$ & $5,137,106(42.4)$ \\
\hline Had a mood/ anxiety disorder (Yes) n(\%) & $1,470,019(11.9)$ & $65,146(22.7)$ & $1,404,873(11.6)$ \\
\hline
\end{tabular}

${ }^{a}$ Weighted distribution 
the family doctor was 4.9 visits/ person/ year [Standard Deviation $(\mathrm{SD})=5.9$ ] for the stroke group, and 3 visits/ person/ year $(\mathrm{SD}=4.8)$ for the non-stroke group. Proportion and mean number of visits to healthcare providers are presented in Table 2.

From the simple pair-wise associations in the stroke group (Table 3), higher income was related to visits to dental practitioners and psychologists (IRR 1.5-8.8), and mood/anxiety disorder was related to visits to family doctors, other medical specialists, psychologists and social worker/counsellors (IRR 1.4-22.1). Age ( $\geq 65$ years), male sex and cardiometabolic comorbid condition was related to visits to eye specialists (IRR 1.7-1.9). Stroke survivors who were able to walk without difficulty (mobility) visited the eye specialists and social worker/counsellors less (IRR 0.2-0.5).

Table 4 shows a summary of IRRs for annual visits to healthcare professionals, comparing stroke and non-stroke groups in the regression models. When unadjusted (Crude Model), stroke survivors visited the family doctor, other medical specialists, nurse, psychologist, social worker/counsellor and audiologist/ speech or occupational therapist significantly more (IRR 1.6-3.7) and visited dental professionals less than people without stroke (IRR 0.7). The stroke survivors had higher visitation rates to these healthcare professionals (IRR 1.6-3.2) than the non-stroke group. After controlling for sociodemographic covariates (age, sex, education and income), the health professions that showed greater visits by stroke survivors in the Crude Model continued to be significant (IRR 1.6-3.2), in addition to visits to physiotherapists and psychologists (Model 1). The models also showed that stroke survivors have higher visitation rates to these healthcare professionals after mobility (IRR 1.3-3.0), mood/anxiety disorder (IRR 1.5-3.3) and cardiometabolic comorbid condition (IRR 1.4-5.1) were controlled (Models 1a - 1c).

\section{Discussion}

The burden that stroke constitutes for patients, their families and the healthcare system is substantial [29]. Corresponding to our hypothesis, stroke survivors were more likely to visit most healthcare professionals than those without stroke using a large population-based sample with a comparison control group without stroke, and this suggests that community-dwelling individuals with stroke need more care and may have greater health needs because of their health condition. Stroke survivors visited the family doctor more than any of the other health professionals. The stroke sample in our study was more likely to visit healthcare professionals that typically manage problems that may arise after a stroke (e.g., family doctor, nurse, physiotherapist, audiologist/speech therapist, occupational therapist, psychologist).

Even after the models were adjusted for sociodemographic variables and the presence of a mobility, mood/ anxiety or cardiometabolic condition, the greater number of health professional visits still remained for the stroke group. It is possible that the severity of these conditions may have influenced the number of visits as only the presence/absence of these conditions was considered, and not a finer gradation such as walking speed for mobility or actual resting blood pressure for cardiometabolic risk. Certainly the mobility impairments of stroke survivors can be complex and severe with partial muscle paralysis, sensory loss, spasticity and ataxia.

There was a much higher prevalence of a mobility impairment, mood/anxiety disorder or cardiometabolic condition in the stroke group compared to the control, and consequently a higher prevalence of having multiple conditions which may require visits to the family doctor. Thus, it is possible that interactions among these conditions may have had impacted the results, for example, mobility problems may contribute to anxiety, while low

Table 2 Mean number of health professional visits reported by samples in the 2014 Canadian Community Health Survey

\begin{tabular}{|c|c|c|c|c|c|c|}
\hline \multirow{2}{*}{$\begin{array}{l}\text { Variable } \\
\text { Visited Healthcare Provider (Yes) }\end{array}$} & \multicolumn{2}{|l|}{ Total } & \multicolumn{2}{|l|}{ Stroke } & \multicolumn{2}{|l|}{ Non-Stroke group } \\
\hline & N (\%) & Mean (SD) & $\mathrm{n}(\%)$ & Mean (SD) & $\mathrm{n}(\%)$ & Mean (SD) \\
\hline Family Doctor & $10,521,679(84.9)$ & $3.0(4.8)$ & $267,142(93.2)$ & $4.9(5.9)$ & $10,254,536(84.7)$ & $3.0(4.8)$ \\
\hline Eye Specialist & $6,235,330(50.3)$ & $1.1(5.8)$ & $157,994(55.1)$ & $1.4(6.9)$ & $6,077,336(50.2)$ & $1.1(5.8)$ \\
\hline Other Medical Specialists & $4,611,415(37.2)$ & $1.1(3.6)$ & $154,815(54.0)$ & $2.2(10.3)$ & $4,456,601(36.8)$ & $1.1(3.2)$ \\
\hline Nurse & $1,503,285(12.1)$ & $0.9(10.4)$ & $79,446(27.7)$ & $3.2(17.6)$ & $1,423,838(11.8)$ & $0.9(10.2)$ \\
\hline Dental Practitioner & $7,901,339(63.7)$ & $1.3(1.6)$ & $125,892(43.9)$ & $1.0(1.8)$ & $7,775,447(64.2)$ & $1.3(1.6)$ \\
\hline Chiropractor & $1,485,209(12.0)$ & $1.1(5.1)$ & $23,912(8.3)$ & $1.1(7.7)$ & $1,461,297(12.1)$ & $1.1(5.0)$ \\
\hline Physiotherapist & $1,588,690(12.8)$ & $1.3(6.9)$ & $46,142(16.1)$ & $1.9(8.1)$ & $1,542,548(12.7)$ & $1.2(6.9)$ \\
\hline Psychologist & $272,087(2.2)$ & $0.2(1.8)$ & $8792(3.1)$ & $0.4(4.2)$ & $263,295(2.2)$ & $0.2(1.7)$ \\
\hline Social Worker/ Counsellor & $429,440(3.5)$ & $0.2(2.8)$ & $29,412(10.3)$ & $0.7(6.4)$ & $400,028(3.3)$ & $0.2(2.1)$ \\
\hline Audiologist/ Speech or Occupational Therapist & $653,850(5.3)$ & $0.1(1.2)$ & $34,038(11.9)$ & $0.4(1.9)$ & $619,812(5.1)$ & $0.1(1.1)$ \\
\hline
\end{tabular}

$\mathrm{N}(\%)$ - Visited healthcare provider at least once during the last 12 months

SD Standard deviation 


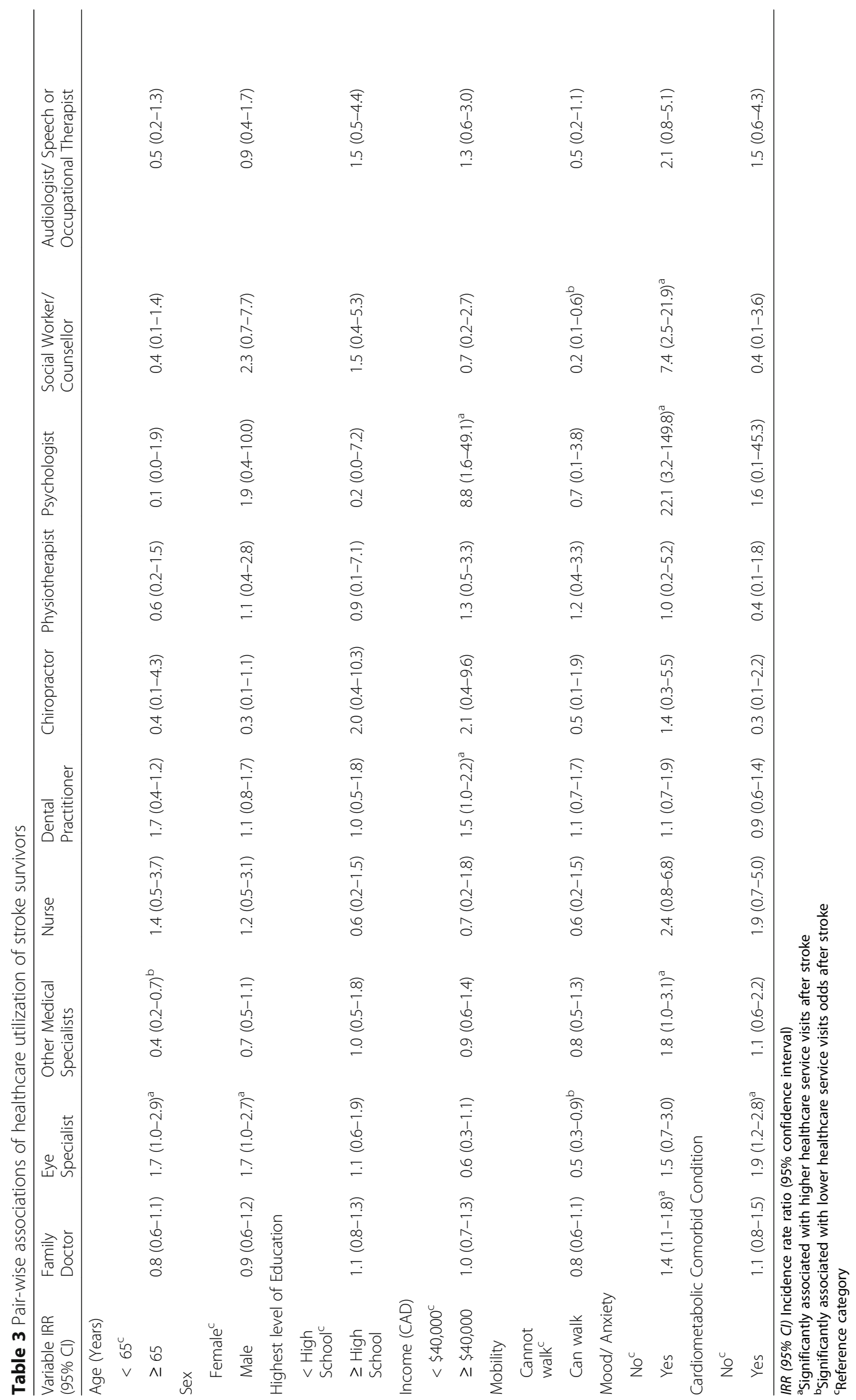


Table 4 Multi-level negative binomial regression models showing the comparison of health professional visits between stroke and non-stroke groups

\begin{tabular}{llllll}
\hline Variable & $\begin{array}{l}\text { Crude Model } \\
\text { IRR }(95 \% \mathrm{Cl})\end{array}$ & $\begin{array}{l}\text { Model 1 } \\
\text { IRR }(95 \% \mathrm{Cl})\end{array}$ & $\begin{array}{l}\text { Model 1a } \\
\text { IRR }(95 \% \mathrm{Cl})\end{array}$ & $\begin{array}{l}\text { Model 1b } \\
\text { IRR }(95 \% \mathrm{Cl})\end{array} \begin{array}{l}\text { Model 1c } \\
\text { IRR }(95 \% \mathrm{Cl})\end{array}$ \\
\hline Family Doctor & $1.6(1.4-1.9)^{\mathrm{a}}$ & $1.6(1.4-1.8)^{\mathrm{a}}$ & $1.3(1.1-1.5)^{\mathrm{a}}$ & $1.5(1.3-1.7)^{\mathrm{a}}$ & $1.4(1.2-1.7)^{\mathrm{a}}$ \\
Eye Specialist & $1.2(0.9-1.7)$ & $1.1(0.8-1.6)$ & $1.0(0.8-1.4)$ & $1.1(0.8-1.5)$ & $1.1(0.8-1.4)$ \\
Other Medical Specialists & $2.0(1.4-2.9)^{\mathrm{a}}$ & $2.0(1.4-2.8)^{\mathrm{a}}$ & $1.7(1.2-2.4)^{\mathrm{a}}$ & $1.9(1.3-2.6)^{\mathrm{a}}$ & $1.9(1.3-2.6)^{\mathrm{a}}$ \\
Nurse & $3.7(2.3-6.1)^{\mathrm{a}}$ & $3.0(1.8-4.8)^{\mathrm{a}}$ & $2.7(1.4-5.2)^{\mathrm{a}}$ & $2.6(1.6-4.2)^{\mathrm{a}}$ & $2.6(1.6-4.1)^{\mathrm{a}}$ \\
Dental Practitioner & $0.7(0.6-0.9)^{\mathrm{b}}$ & $0.9(0.7-1.1)$ & $0.9(0.8-1.2)$ & $0.9(0.7-1.1)$ & $0.9(0.7-1.1)$ \\
Chiropractor & $1.0(0.4-2.5)$ & $1.3(0.5-2.5)$ & $1.2(0.5-2.6)$ & $1.2(0.5-2.9)$ & $1.2(0.5-2.9)$ \\
Physiotherapist & $1.5(0.9-2.5)$ & $1.8(1.1-1.9)^{\mathrm{a}}$ & $1.8(1.1-2.9)^{\mathrm{a}}$ & $1.8(1.2-2.9)^{\mathrm{a}}$ & $1.9(1.1-3.1)^{\mathrm{a}}$ \\
Psychologist & $2.9(0.3-29.8)$ & $4.0(1.1-5.7)^{\mathrm{a}}$ & $4.5(0.7-30.1)^{\mathrm{a}}$ & $6.2(0.4-90.1)^{\mathrm{a}}$ & $4.1(0.7-22.5)$ \\
Social Worker/ Counsellor & $3.1(1.7-5.6)^{\mathrm{a}}$ & $3.2(2.2-4.8)^{\mathrm{a}}$ & $3.0(1.5-5.8)^{\mathrm{a}}$ & $3.3(1.6-6.9)^{\mathrm{a}}$ & $5.1(1.9-13.1)^{\mathrm{a}}$ \\
Audiologist/ Speech or Occupational Therapist & $3.2(1.9-5.4)^{\mathrm{a}}$ & $2.9(1.2-2.1)^{\mathrm{a}}$ & $2.5(1.3-5.1)^{\mathrm{a}}$ & $2.9(1.6-5.3)^{\mathrm{a}}$ & $2.9(1.7-5.1)^{\mathrm{a}}$ \\
\hline
\end{tabular}

Crude Model - Unadjusted incidence rate ratios

Model 1 - Incidence rate ratios were adjusted for age, sex, education and income

Model $1 \mathrm{a}$ - Incidence rate ratios were adjusted for age, sex, education, income and mobility

Model $1 \mathrm{~b}$ - Incidence rate ratios were adjusted for age, sex, education, income and mood/anxiety disorder

Model 1c - Incidence rate ratios were adjusted for age, sex, education, income and presence of cardiometabolic comorbid condition

IRR (95\% Cl) Incidence rate ratio (95\% confidence interval)

${ }^{a}$ Stroke survivors significantly associated with higher healthcare service visits than those without stroke

${ }^{b}$ Stroke survivors significantly associated with lower healthcare service visits than those without stroke

mood may deter one from activities that keep one mobile. Interestingly, stroke survivors with walking difficulties visited a social worker/counsellor around five times more often than stroke survivors without a walking difficulty. A number of explanations may account for this finding, including the evidence that those with walking difficulties have more psychosocial difficulties [30] or the role of social workers in organizing mobility and transportation services to address physical impairments [31]. In addition, other mediators may be involved as mobility ability has been shown to relate to overall stroke severity [32] and social workers/counsellors likely prioritize individuals who are more impacted by their stroke.

The greatest discrepancy in visits was with psychologists where stroke survivors visited four to six times that of people without stroke. Stroke survivors with mood/ anxiety disorders were far more likely to visit a psychologist, but not their family doctor than stroke survivors without a mood/anxiety disorder. Furthermore, while 22.7 and $11.6 \%$ of the stroke and non-stroke groups reported a mood/anxiety disorder, the proportions visiting a psychologist were very small (2-3\% in both groups). Stigmas, as well as a lack of knowledge about mental health symptoms and treatments may prevent people from seeking treatment for depression or anxiety; a US national study of 21,000 males showed that less than $50 \%$ sought treatment, despite experiencing depression or anxiety on a daily basis [33]. Psychological disorders have also been linked to greater dependence in activities of daily living, poorer quality of life after stroke [34] and higher utilisation of healthcare services if untreated [35-
37]. A barrier to most community-based psychological services is the fact that they are delivered by private services, making it unaffordable for many people [38]. Also, psychological services are not covered by health insurance, making it even more unaffordable. Sixty-five percent of Canadians have private health insurance which pays for the health-care expenditures that go towards other professionals (dentists, optometrists and physiotherapists, among others) [39]. Private health insurance has been suggested to be a predictor of improved outcomes after stroke [40].

The findings from this study have considerable importance and implications as this study was based on a large sample of adults with or without stroke in Canada. The results suggest that stroke survivors have stroke-related health needs that requires more visits to healthcare professionals than people without stroke. Stroke survivors with disabilities usually require care that can be complex due to their multiple needs. These individuals might need to consult several healthcare professionals for different medical conditions. Their complex care requires easy accessibility to healthcare services professionals. It is essential for the healthcare system to be responsive to these needs. Interdisciplinary health services delivery programs, involving healthcare professionals crucial to stroke management, should be developed for the care of these patients.

There are several limitations that warrant acknowledgment in this study. Firstly, stroke and other conditions were self-reported by individuals and not verified by any other source. Self-report measures are easily implemented to large samples, but have limitations such as 
recall/ response bias, introspective ability and social desirability bias. The study involved only people living in private households, therefore, the results may not be generalized to all stroke survivors as there are some who are residents of healthcare institutions. As administrative data were used, many variables that were potential cofounders of stroke were not assessed or provided, including clinical parameters (such as stroke type, stroke severity), family structure and support network, as well as use of other healthcare resources, such as ambulance use and emergency room admissions. Therefore, not all probable cofounding factors of stroke were adjusted for because the details were not available in this study. We adjusted for mobility and comorbidities, but we were not able to adjust for other determinants of stroke outcomes such as stroke type and severity (however, mobility can be considered one surrogate for severity). Further studies that will include more detailed stroke risk factors and comorbidities are needed to address these limitations.

\section{Conclusion}

Stroke survivors visited healthcare professionals more than people without stroke, and were more likely to visit those that manage problems that may arise after a stroke (e.g., family doctor, nurse, psychologist, physiotherapist). The effects of a stroke include mobility impairment and mood/ anxiety disorders. Therefore, adequate access to stroke-related healthcare services should be provided for stroke survivors, as this may improve functional outcome and reduce future healthcare costs.

\section{Abbreviations \\ CFI: Canadian Foundation for Innovation; Cl: 95\% confidence intervals; CIHR: Canadian Community Health Survey; CIHR: Canadian Institutes of Health Research; CRDCN: Canadian Research Data Centre Network; IRR: Incidence rate ratios; SD: Standard deviation; SSHRC: Social Sciences and Humanities Research Council}

\section{Acknowledgments}

Data for this work were collected by Statistics Canada and provided by the University of British Columbia Research Data Centre.

\section{Funding}

Funding from the Canadian Institutes of Health Research (CIHR FDN 143340) and the Canada Research Chairs Program to JE supports this study. AO is supported by a CIHR Postdoctoral Fellowship and the Michael Smith Foundation for Health Research Trainee Award. This research was supported by funds to the Canadian Research Data Centre Network (CRDCN) from the Social Sciences and Humanities Research Council (SSHRC), the Canadian Institutes of Health Research (CIHR), the Canadian Foundation for Innovation $(\mathrm{CFI})$, and Statistics Canada. Although the research and analysis are based on data from Statistics Canada, the opinions expressed do not represent the views of Statistics Canada. The funding bodies had no role in the design of the study and collection, analysis, and interpretation of data and in writing the manuscript.

\section{Availability of data and materials}

The datasets used and/or analysed during the current study are available from the University of British Columbia Research Data Centre for researchers who meet the criteria for access to confidential data.

\section{Authors' contributions}

AO JE conceived and designed the study and drafted the manuscript; AO JE LS analysed and interpreted the data, and revised the manuscript; BS interpreted the data and reviewed the manuscript. All authors read and approved the final manuscript.

\section{Ethics approval and consent to participate}

Not applicable.

\section{Consent for publication}

Not applicable.

\section{Competing interests}

JE (Operating grant) and AO (Fellowship) have received financial support for research from the Canadian Institutes of Health Research (CIHR). LS and BS declare that they have no competing interests.

\section{Publisher's Note}

Springer Nature remains neutral with regard to jurisdictional claims in published maps and institutional affiliations.

\section{Author details}

${ }^{1}$ Department of Physical Therapy, The University of British Columbia, Vancouver, Canada. ${ }^{2}$ Rehabilitation Research Program, GF Strong Rehab Centre, Vancouver Coastal Health Research Institute, Vancouver, Canada. ${ }^{3}$ Graduate Program in Rehabilitation Sciences, The University of British Columbia, Vancouver, Canada.

Received: 10 October 2018 Accepted: 18 March 2019

Published online: 27 March 2019

\section{References}

1. Ovbiagele B, Nguyen-Huynh MN. Stroke epidemiology: advancing our understanding of disease mechanism and therapy. Neurotherapeutics. 2011; 8:319-29. https://doi.org/10.1007/s13311-011-0053-1.

2. Seshadri S, Beiser A, Kelly-Hayes M, Kase CS, Au R, Kannel WB, et al. The lifetime risk of stroke: estimates from the Framingham study. Stroke. 2006; 37:345-50.

3. Feigin $\mathrm{VL}$, Forouzanfar $\mathrm{MH}$, Krishnamurthi $\mathrm{R}$, Mensah GA, Connor M, Bennett DA, et al. Global and regional burden of stroke during 1990-2010: findings from the global burden of disease study 2010. Lancet Lond Engl. 2014;383: 245-54

4. Donabedian A. Aspects of medical care administration: specifying requirements for health care. Cambridge, MA: Harvard University Press; 1973.

5. Da Silva R, Contandriopoulos A, Pineault R, Tousignant PA. Global approach to evaluation of health services utilization: concepts and measures. Healthc Policy. 2011:6:e106-17.

6. Cook C, Stickley L, Ramey K, Knotts VJ. A variables associated with occupational and physical therapy stroke rehabilitation utilization and outcomes. J Allied Health. 2005;34:3-10.

7. Ullberg T, Zia E, Petersson J, Norrving B. Doctor's follow-up after stroke in the south of Sweden: an observational study from the Swedish stroke register (Riksstroke). Eur Stroke J. 2016;1:114-21. https://doi.org/10.1177/ 2396987316650597

8. de Haan R, Limburg M, van der Meulen J, van den Bos GA. Use of health care services after stroke. Qual Health Care QHC. 1993;2:222-7.

9. Vincent C, Robichaud L, Rousseau J, Viscogliosi C, Talbot LR, Desrosiers J, et al. Rehabilitation needs for older adults with stroke living at home: perceptions of four populations. BMC Geriatr. 2007;7. https://doi.org/10. 1186/1471-2318-7-20.

10. Talbot LR, Viscogliosi C, Desrosiers J, Vincent C, Rousseau J, Robichaud L. Identification of rehabilitation needs after a stroke: an exploratory study. Health Qual Life Outcomes. 2004;2:53.

11. Chan L, Wang H, Terdiman J, Hoffman J, Ciol MA, Lattimore BF, et al. Disparities in outpatient and home health service utilization following stroke: results of a 9-year cohort study in northern California. PM\&R. 2009;1: 997-1003. https://doi.org/10.1016/j.pmrj.2009.09.019.

12. Ghose SS, Williams LS, Swindle RW. Depression and other mental health diagnoses after stroke increase inpatient and outpatient medical utilization three years poststroke. Med Care. 2005;43:1259-64. 
13. Aziz NA, Pindus DM, Mullis R, Walter FM, Mant J. Understanding stroke survivors' and informal carers' experiences of and need for primary care and community health services - a systematic review of the qualitative literature: protocol: table 1. BMJ Open. 2016;6:e009244. https://doi.org/10.1136/ bmjopen-2015-009244.

14. Forster A, Mellish K, Farrin A, Bhakta B, House A, Hewison J, et al. Development and evaluation of tools and an intervention to improve patient- and carercentred outcomes in longer-term stroke care and exploration of adjustment post stroke: the LoTS care research programme. Programme Grants Appl Res. 2014;2:1-224. https://doi.org/10.3310/pgfar02060.

15. Cabral NL, Muller M, Franco SC, Longo A, Moro C, Nagel V, et al. Three-year survival and recurrence after first-ever stroke: the Joinville stroke registry. BMC Neurol. 2015;15. https://doi.org/10.1186/s12883-015-0317-1.

16. Karatepe A, Gunaydin R, Kaya T, Turkmen G. Comorbidity in patients after stroke: impact on functional outcome. J Rehabil Med. 2008:40:831-5. https://doi.org/10.2340/16501977-0269.

17. Winstein CJ, Stein J, Arena R, Bates B, Cherney LR, Cramer SC, et al. Guidelines for adult stroke rehabilitation and recovery: a guideline for healthcare professionals from the American Heart Association/American Stroke Association. Stroke. 2016;47:e98-169. https://doi.org/10.1161/STR. 0000000000000098 .

18. Clarke A, Rosen R. Length of stay. How short should hospital care be? Eur J Pub Health. 2001;11:166-70.

19. Statistics Canada. Canadian community health survey - annual component (CCHS). 2014. http://www23.statcan.gc.ca/imdb/p2SV.pl?Function= getSurvey\&SDDS=3226. Accessed 27 Jan 2017.

20. Statistics Canada. Canadian community health survey (CCHS) annual component - 2014 questionnaire. 2014. http://www23.statcan.gc.ca/imdbbmdi/instrument/3226_Q1_V11-eng.pdf. Accessed 27 Jan 2017.

21. Alemayehu B, Warner KE. The lifetime distribution of health care costs. Health Serv Res. 2004;39:627-42. https://doi.org/10.1111/j.1475-6773 2004.00248.x.

22. Kissela BM, Khoury JC, Alwell K, Moomaw CJ, Woo D, Adeoye O, et al. Age at stroke: temporal trends in stroke incidence in a large, biracial population. Neurology. 2012;79:1781-7.

23. Public Health Agency of Canada. Stroke in Canada highlights from the Canadian chronic disease surveillance system. Ottawa: Public Health Agency of Canada; 2017. http://publications.gc.ca/collections/collection_2018/aspcphac/HP35-88-2017-eng.pdf. Accessed 21 Mar 2018.

24. Singhpoo K, Charerntanyarak L, Ngamroop R, Hadee N, Chantachume W, Lekbunyasin $\mathrm{O}$, et al. Factors related to quality of life of stroke survivors. J Stroke Cerebrovasc Dis. 2012;21:776-81. https://doi.org/10.1016/j. jstrokecerebrovasdis.2011.04.005.

25. Nichols-Larsen DS, Clark PC, Zeringue A, Greenspan A, Blanton S. Factors influencing stroke survivors' quality of life during subacute recovery. Stroke. 2005;36:1480-4.

26. Gruneir A, Griffith LE, Fisher K, Panjwani D, Gandhi S, Sheng L, et al. Increasing comorbidity and health services utilization in older adults with prior stroke. Neurology. 2016;87:2091-8.

27. Broomfield NM, Quinn TJ, Abdul-Rahim AH, Walters MR, Evans JJ. Depression and anxiety symptoms post-stroke/TIA: prevalence and associations in cross-sectional data from a regional stroke registry. BMC Neurol. 2014;14:198.

28. Ryan BL, Shadd J, Maddocks H, Stewart M, Thind A, Terry AL. Methods to describe referral patterns in a Canadian primary care electronic medical record database: modelling multilevel count data. J Innov Health Inform. 2017;24:888.

29. Public Health Agency of Canada. Tracking heart disease and stroke in Canada - stroke highlights 2011. 2012. www.phac-aspc.gc.ca/cd-mc/cvdmcv/sh-fs-2011/index-eng.php. Accessed 3 May 2017.

30. Mehta KM, Yaffe K, Brenes GA, Newman AB, Shorr RI, Simonsick EM, et al. Anxiety symptoms and decline in physical function over 5 years in the health, aging and body composition study. J Am Geriatr Soc. 2007; 55:265-70.

31. Padberg I, Knispel P, Zöllner S, Sieveking M, Schneider A, Steinbrink J, et al. Social work after stroke: identifying demand for support by recording stroke patients' and carers' needs in different phases after stroke. BMC Neurol. 2016;16. https://doi.org/10.1186/s12883-016-0626-z.

32. Kwah LK, Harvey LA, Diong J, Herbert RD. Models containing age and NIHSS predict recovery of ambulation and upper limb function six months after stroke: an observational study. J Physiother. 2013;59:189-97.
33. Blumberg SJ, Clarke TC, Blackwell DL. Racial and ethnic disparities in men's use of mental health treatments. NCHS Data Brief. 2015;206:1-8.

34. Burton L-J, Tyson S. Screening for mood disorders after stroke: a systematic review of psychometric properties and clinical utility. Psychol Med. 2015;45: 29-49. https://doi.org/10.1017/S0033291714000336.

35. Hackett ML, Anderson CS, House A, Xia J. Interventions for treating depression after stroke. In: The cochrane collaboration, editor. Cochrane database of systematic reviews. Chichester: Wiley; 2008. https://doi.org/10. 1002/14651858.CD003437.pub3.

36. Watkins $C L$, French B. Psychological intervention poststroke: ready for action? Stroke. 2009;40:2951-2. https://doi.org/10.1161/STROKEAHA 109.562348

37. Kotila M, Numminen $\mathrm{H}$, Waltimo $\mathrm{O}$, Kaste M. Post-stroke depression and functional recovery in a population-based stroke register. The Finnstroke study. Eur J Neurol. 1999:6:309-12.

38. Moulding R, Grenier J, Blashki G, Ritchie P, Pirkis J, Chomienne M-H. Integrating psychologists into the Canadian health care system: the example of Australia. Can J Public Health Rev Can Sante Publique. 2009;100: $145-7$.

39. Hogg-Johnson S, Cole DC, Lee H, Beaton DE, Kennedy C, Subrata P, et al. Changes in physiotherapy utilization in one workforce: implications for accessibility among Canadian working-age adults. Healthc Policy Polit Santé 2011;6:e93-108

40. Fargen KM, Neal D, Blackburn SL, Hoh BL, Rahman M. Health disparities and stroke: the influence of insurance status on the prevalence of patient safety indicators and hospital-acquired conditions. J Neurosurg. 2015;122:870-5. https://doi.org/10.3171/2014.12.JNS14646.

\section{Ready to submit your research? Choose BMC and benefit from:}

- fast, convenient online submission

- thorough peer review by experienced researchers in your field

- rapid publication on acceptance

- support for research data, including large and complex data types

- gold Open Access which fosters wider collaboration and increased citations

- maximum visibility for your research: over 100M website views per year

At $\mathrm{BMC}$, research is always in progress.

Learn more biomedcentral.com/submissions 